\title{
Imposed Relevance: On the Sociological Use of a Phenomenological Concept
}

\author{
Andreas Göttlich \\ Universität Konstanz \\ andreas.goettlich@uni-konstanz.de
}

\begin{abstract}
The present paper discusses the concept of imposed relevance as developed by Alfred Schutz. The discussion acts on the assumption that within his writings there are two different usages of the concept: a phenomenological one and a sociological one. The argument states that both usages may not be confused-a failure which might be induced by the fact that Schutz himself never dwelled on their correlation. This being said, this paper presents some basic considerations which try to utilize phenomenological reflections for sociological analyses, keeping in mind that the difference between them may not be blurred.
\end{abstract}

Keywords: Relevance, Power, Social Imposition, Phenomenology vs. Sociology

One of the most frequent accusations directed at phenomenologically orientated sociology in the tradition of Alfred Schutz, is its assumed lack of considerations of power relations. The life-world is supposed to be a "harmless place" (cf. Srubar 2007) where individuals intersubjectively construe shared systems of relevance on a level playing field. Although at least some of the writings within the Schutzian paradigm encourage this (mis-)interpretation, one must insist that the pertinent critique falls short of Schutz's principal approach. His concept of imposed relevance, as introduced in his Reflections on the Problem of Relevance, and later used in various applied studies, provides a useful tool for analyzing power relations from a subjective point of view. Therefore the deficiency in question is not so much a fundamental problem, but rather a problem of missing elaboration in Schutz's work. The deficit is explained by the contingent fact that Reflections remained a fragment, which in particular lacks a profound analysis 
of the social imposition of relevance, which can be regarded as the core phenomenon of power relations. Having said this, the present paper focuses on the concept of imposed relevance and its possible impact on sociological research. It presents some basic thoughts which might prove helpful for further developing a phenomenologically informed sociology of power.

In order to facilitate understanding, the following argumentation is subdivided into several theses. The first of these simply states that the concept of imposed relevance - the way it was introduced by Schutz in his Reflections-is a phenomenological, not a sociological term. This thesis may appear trivial, as Schutz himself was quite clear on this point. Yet, it becomes significant in connection with the second thesis, which states that in the scientific literature relating to Schutz, and even in his own so-called "applied studies," the concept is frequently used for sociological description without having previously clarified one important question: is it possible to simply add sociological reflections on imposed relevance to the phenomenological considerations presented in Reflections, or does the perspective have to be changed in order to enable an enhancement of this kind? If one ignores this question, one runs the risk of confusing constitutional (philosophical) and constructional (empirical) analysis. Therefore, the third thesis observes the necessity to further elaborate the connection between the phenomenological and the sociological use of the concept of imposed relevance. Calling into question one of the criteria that Schutz uses for distinguishing between free and imposed relevance, an alternative theoretical proposal is made, which tries to utilize philosophical reflection for empirical research. Accordingly, the fourth and last thesis states the need for a sociological adaptation of the phenomenological concept.

Thesis 1: The concept of imposed relevance — the way it was introduced by Schutz in his "Reflections on the Problem of Relevance"-is a phenomenological, not a sociological concept.

This first statement is, I assume, the least controversial of my four theses, so I will dwell only shortly on it. At the very end of his book The Phenomenology of the Social World, Schutz hints at the problem of relevance as a topic for further investigation. He states that "the definitive clarification of this problem will be possible only through an over-all phenomenological analysis" (Schutz 1997: 249). This is exactly what he tried to accomplish with his Reflections 15 years later. In fact, in this text Schutz only seldom uses the terms "sociological" or "phenomenological," yet the principal framework of his enterprise makes it clear that he is "not primarily orientated towards concrete issues of sociological analysis, but rather towards the clarification of basic theoretical questions."

1 Transl. by the author; the German original reads: „nicht primär an konkreten Themen soziologischer Analyse, sondern an der Klärung grundlagentheoretischer Fragen orientiert.“ 
This estimation by Elisabeth List (2004: 10), who edited Schutz's manuscript on relevance in the Alfred Schütz Werkausgabe, is supported by the fact that in his manuscript he deliberately makes no statements about the social world. Because of methodological considerations, he begins by reflecting on the situation of the solitary individual in its "natural" surrounding, and delays the contemplation of social relationships to the later parts of his treatise. In an interim summary, Schutz himself critically remarks "the omission made thus far [...] that we have handled our problem [...] as if there were no social world at all, as if an isolated individual experienced the world of nature disconnected from his fellowmen" (Schutz 2011: 135). This is the same procedure he previously used in The Phenomenology of the Social World, yet in contradistinction to this book, his unfinished Reflections on the Problem of Relevance ends before it broaches the issue of the social world. As a consequence, in this manuscript the topic of socially imposed relevance remains uncovered.

Thesis 2: In empirical analyses relating to Schutz and also in his own so-called "applied studies," the concept of socially imposed relevance is frequently used without elaborating on the difference between constitutional (phenomenological) and constructional (sociological) analysis.

According to my first thesis, the concept of socially imposed relevance lacks phenomenological clarification in the work of Schutz. This circumstance has not prevented him and others from using this term within the context of sociological analysis, somehow contradicting his own claim of providing a philosophical foundation of the social sciences. Due to the size of this paper, I will concentrate on Schutz's own writings and mention only two examples. In his paper "Equality and the Meaning Structure of the Social World," he uses the concept of socially imposed relevance in order to define the phenomenon of social discrimination: "discrimination," says Schutz, "presupposes both imposition of a typification from the objective point of view and an appropriate evaluation of this imposition from the subjective viewpoint of the afflicted individual" (1964a: 261). And in his essay "The Well-informed Citizen," he makes the case that due to increasing social anonymity, the zone of socially imposed relevances will grow in modern times (cf. 1964b: 129). Both theses are highly significant for empirical sociological analysis, and Schutz himself points out that within this context the concepts of imposed and intrinsic relevances are "merely constructive types" (1964b: 126). This remark certainly raises the question of a phenomenological analysis of the constitution of socially imposed relevance within the consciousness of the individual, in contradistinction to its social construction (cf. Luckmann 2007): is there something like an eidos that we can call "social imposition" and that we can describe by means of phenomenology (i.e., as a universal structure of the life-world) —or is "social imposition" merely a social construction, to be analyzed by means of empirical re-construction? 
The fact that there is a link missing between the constructional and the constitutional usage of the concept is aptly illustrated by The Structures of the Life-World. In this work, Thomas Luckmann obviously intends to mend what Schutz's manuscript lacks, and so he introduces the concept of socially imposed relevance. Yet his according reflections are rather scarce and they only refer to one of the three types of relevance differentiated by Schutz, namely to that of thematic relevance. Although we learn that forced attention "in daily life ... is of the greatest importance" (Schutz/Luckmann 1973: 190), Luckmann gives no phenomenological description of the way in which this forced attention is constituted in the consciousness of the afflicted individual. Thus, The Structures of the Life-World provides only little insight exceeding Reflections.

Thesis 3: The connection between the phenomenological and the sociological use of the concept of imposed relevance needs to be reflected upon more deeply by elaborating the friction between both usages.

At this point, it is necessary to go into greater detail regarding the content of Schutz's theory of relevance. As already mentioned, Schutz distinguishes between three types of relevance-thematic, interpretational, and motivational relevance - and divides all of them into free or intrinsic relevances on the one hand, and imposed or bound relevances on the other. This can be summarized in the following cross-tabulation:

\begin{tabular}{c|c|c} 
& free (intrinsic) & imposed (bound) \\
\hline thematic relevance & voluntary advertence & forced attentiveness \\
\hline interpretational relevance & explication of a problem & routine coincidence \\
\hline motivational relevance & in-order-to motive & because-of motive
\end{tabular}

Table 1: Types offreelimposed relevance

If one looks for the criteria which Schutz uses to draw the line of demarcation between free and imposed relevance, one finds the opposition between familiarity and unfamiliarity in the case of thematic relevance, the opposition between actuality and latency in the case of interpretational relevance, and the aspect of time in the case of motivational relevance. According to the first criterion, a thematic relevance is perceived as free when we are familiar with it, whereas unfamiliarity interrupts the idealizations of "and so on" and "again and again," which is why the according topic is perceived as imposed. According to the second criterion, interpretational relevances which lie within the grasp of our consciousness are regarded as free, whereas relevances that lie beyond this grasp are regarded as imposed. Finally, the third criterion of time is aptly illustrated by the distinction between because-of-motives and in-order-to-motives: because-of-motives 
are defined as imposed relevances, as their constitution reaches back in time and their ongoing existence determines our current action. In contradistinction, in-order-to-motives are defined as free relevances, as they are projected into the future which principally can be changed.

In the following I will concentrate on the type of motivational relevance and therewith on the criterion of time, which in my opinion a) needs further investigation and b) has the potential to lead over to sociological considerations. This can be illustrated by using an example from the world of literature. In an episode in Dostoyevsky's The Brothers Karamazov (Dostoyevsky 2010), the eldest of the brothers, Dmitri Karamazov, acquires a notable amount of money. For a specific reason, he is determined not to spend the money for a certain span of time. As Dmitri knows his own unsteady character, he is aware of the fact that he cannot simply rely on the fortitude of his own resolution, which although made in earnest at that moment in time, may well be superimposed by concurring motivations later in time. To solve the problem of not being able to trust himself, he sews the money into the lining of his cloak in order to prevent himself from accessing it in the future. In other words, the present Dmitri confines the freedom of action for the future Dmitri.

At first glance, the example provides an accurate illustration of Schutz's statement that motives of action which have been constituted in the past (i.e. becauseof-motives) are experienced by the present ego as imposed, whereas they are regarded as free in the very moment of their constitution: Dmitri 1, who sews the money into the lining of his cloak, freely disposes of the money, whereas Dmitri 2, who carries the money along with him, is constrained by the previous act of Dmitri 1. Drawing from Schutz's manuscript, Das Problem der Personalität in der Sozialwelt (2003) where he distinguishes between three temporalities of the ego, we can say that the present ego imposes relevances upon the future ego, and respectively that the present ego is subject to relevances imposed upon itself by the former ego.

If one looks closer, however, the example proves to be more complex. Why is the present ego confined by the motivations of the former ego at all? Can decisions not be principally revised? Certainly decisions, respectively the resulting actions, may influence facts in a way that hinders subsequent action in the future, and we may even deliberately choose our actions in a way to make certain future acts impossible. However, to erect actual barriers for future action is a rather complex task which we can perform only seldom. More often we can simply construct minor obstacles that are mere reminders that we once set certain relevances. This is exactly the case with Dmitri Karamazov, who could simply tear the money out of the lining of his cloak and thus revise his previous decision.

So we need an explanation for Schutz's assumption that motivations which were constituted in the past are experienced as imposed ones. The general consideration that man is a creature of habit, and that therefore relevances are principally characterized by continuance does not suffice, as it does not explain why 
we revise some decisions more easily than others. The thesis I would like to submit, is that an explanation must be sought with regard to the relation of the different temporalities of the ego. Schutz himself hints at the possibility that a former ego can fade away in the course of time, so that the present ego no longer identifies with it. Thus one may argue that in such cases the present ego experiences the relevances set by this former ego as imposed ones-they are perceived in almost the same way as if they had been determined by a different person. On the other hand, if the former ego is accepted by the present ego as a constitutive part of its biographical identity, then the latter will not perceive the decisions of the former as impositions.

Referring exactly to this relation between different temporalities of the ego, the German philosopher Theodor Litt (1926) introduced the concept of the reciprocity of perspectives, which Schutz later used in order to explain the possibility of an intersubjectively shared world with common meaning (cf. Schutz 1962a: 11ff., 1962b: 315f.). Before considering the social world, however, Litt refers to cases where the present ego regards the point of view of the former ego as a distinct perspective-illustrated by the fictitious statement "this once was me"2 (Litt 1926: 84). The term reciprocity is meant to underline the discreteness of the perspective of the former ego, opposing an understanding which reduces the past to a mere derivative of the present. Thus, starting from Schutz's distinction between the temporalities of the ego, and in addition relating to Litt's considerations, we can state that the stronger the reciprocity of perspectives between former and present ego turns out to be, the weaker the tendency to perceive motivations determined in the past as imposed will be-after all, it was the ego itself that constructed them. Vice versa, the weaker the reciprocity of perspectives between former and present ego is, the stronger the tendency to perceive motivations determined in the past as imposed will be. This latter case is illustrated by Dmitri Karamazov, who knows in advance that his future ego will some day abolish his decision to save the money and therefore sews it into the lining of his cloak in order to impede the anticipated change of opinion (or more precisely: its implementation). The money sewn into the lining is not only a mark, which is meant to overcome the transcendence of time, but also a sign, which is meant to overcome the intrasubjective transcendence between two persons: the current and the future ego.

From my point of view, Litt's concept provides a theoretical figure which is able to give at least a formal explanation as to why motives which were set in the past are sometimes experienced as imposed and sometimes not: the clue seems to be reciprocity which here can be defined according to the degree of overlapping between the interpretational relevances of the present and the former ego, as it is those relevances from which ego's motivations spring. This approach has the considerable advantage that it can be expanded to the social sphere (as, by the

2 Transl. by the author; the German original reads: "das war ich einmal." 
way, Litt did himself). ${ }^{3}$ So far, I have only talked about the solitary individual and in this context I have modified the example of Dmitri Karamazov. In fact, Dmitri obtains the money in question from another person, a woman whom he very much adores. Dmitri promises her to keep the money for a while and to return it thereafter. In this version, the case becomes more complex, yet the additional social dimension can be described by pursuing the insights gained when reflecting on the solitary Dmitri.

In the same way as it appears to be misleading to principally define becauseof-motives as bound relevances, it would be wrong to generally classify all motivations of the ego that are somehow evoked by the action of others as socially imposed relevances. ${ }^{4}$ The sole fact that relevances that originate in the past influence our current behavior does not necessarily mean that we experience them as bound. In the same way, the sole fact that relevances which are set by others influence our own behavior does not necessarily mean that we experience them as imposed. In both cases the answer to the question whether a relevance is perceived as intrinsic or bound, depends on the relation between two persons: the intrasubjective relation between current and former ego in the one case, and the intersubjective relation between ego and alter in the other. The concept of reciprocity provides the clue with regard to the aspect of time as well as to the aspect of sociality. If the ego assumes a strong reciprocity of schemes of apperception, appresentation, and interpretation, then it is inclined to regard motivations constituted by the former or by the alter ego as intrinsic. On the contrary, if it assumes only a weak reciprocity, then it tends to perceive such motivations as imposed ones.

It is important to point out that in social reality both dimensions frequently correlate: a motive determining the actual behavior of ego has often been constituted by alter and adopted by a former ego-as it is the case with Dmitri Karamazov. This correlation between time and sociality is characteristic for contracts which, in the juridical sense, define a considerable amount of our social relations, and even more so in the metaphorical sense provided by Thomas Hobbes. The commitments which one enters into when signing a contract will be perceived as imposed, the more one assumes a weak reciprocity with regard to the partner, and the more the former ego which signed the contract fades away over the course of time. On the contrary, if one assumes a strong reciprocity with regard to the partner, and if the former ego, which signed the contract, is still seen as a part of the biographical identity, then one is more inclined to

\footnotetext{
3 A similar connection between time and sociality becomes apparent in the following remark by Husserl (1999: 115): "Somewhat as my memorial past, as a modification of my living present, 'transcends' my present, the appresented other being 'transcends' my own being." See also Schutz's term "autobiographical sociality" (1996a: 196), introduced in his paper "On the Concept of Horizon."

${ }^{4}$ One may detect a certain tendency to this direction in Schutz's reflections on the motivational context of social interaction (1997: 159ff.).
} 
regard said commitments as intrinsic. The fact that the observance of contracts is usually supervised by state authorities, using the threat of juridical sanctions, reacts to the case of weak reciprocity, where the moment of inner conviction is outweighed by the moment of external force. What Emile Durkheim (1998) described as "non-contractual elements of contracts," on the other hand, refers to the case of strong reciprocity, without which contractualism could not possibly work as a general means of social integration.

Thesis 4: In order to use the concept of imposed relevance for the description of social relations one has to adapt its original phenomenological elaboration.

The considerations so far have led to the result that the talk of socially imposed relevance must take into consideration the element of reciprocity. The latter has indeed been described by Schutz as a formal element of the general structures of the life-world, that is, as a general thesis performed in the natural attitude of everyday life. However, in its phenomenological form, which explains the basic assumption of a world of common meaning, this concept does not suffice with regard to the problem at hand. In order to discern between imposed and free motives of action in a way that is able to reflect the actual perception of living individuals, we must differentiate between suppositions of reciprocity that have stood the test of time so far, and suppositions of reciprocity that have failed - a failure which does not affect the general thesis. In other words, we have to take into consideration the concrete social situation with its particular unique history, rather than making statements on the general structure of the life-world.

To sum up, a mundane phenomenology can only consolidate the empirical reconstruction of acts of social imposition of relevance, but cannot replace it. It is also worth adding that a transcendental phenomenological approach likewise offers no solution. Following a transcendental approach, the differentiation would have to be sought within the primordial sphere of the ego which is won by the epoché of the psychic events pertaining to the alter ego (fremdpsychische Vorgänge), as performed in Husserl's $5^{\text {th }}$ Cartesian Meditation (cf. Husserl 1999: 89ff.). Husserl resists the allegation that the transcendental ego uncovered by this performance would be bound to solipsism by insisting that "the psychic life of my Ego [...], including my whole world-experiencing life and therefore including my actual and possible experience of what is other, is wholly unaffected by screening off what is other" (ibid:: 98; original emphasis). It would be an "illusion," Husserl argues, "that everything I, qua transcendental ego, know as existing in consequence of myself, and explicate as constituted in myself, must belong to me as part of my own essence" (ibid:: 149; original emphasis).

For the problem at hand this would mean that within the primordial sphere a differentiation between proper (intrinsic) and alien relevances (and as a subcategory of them: imposed ones) is principally possible, as the transcendental 
ego has, at least potentially, consciousness of other egos. And yet, by screening off their psychic events, the latter are reduced to mere bodies ${ }^{5}$ - bodies which must be filled with inner life again by acts of appresentation. "For reasons of method," Husserl writes, "the actuality for me of what is other ... shall ... remain excluded from the theme" (ibid.: 94), according to the fundamental "proposition that everything existing for me must derive its existential sense exclusively from me myself, from my sphere of consciousness" (ibid.: 150). Now, whatever philosophical benefit the contemplation of such existential sense might bring, it seems obvious that this sense must necessarily differ from the meaning which derives from social interaction with real contemporaries of flesh and blood, and so a transcendental approach cannot help in empirically reconstructing acts of social imposition of relevance.

If the above argumentation is correct, then phenomenology—transcendental as well as mundane-would be overcharged with providing a universal criterion which marks the turnover where alien relevances become proper ones. Therefore, it cannot replace the empirical reconstruction of first-order-constructions of socially imposed relevance. However, it teaches the importance of the subjective point of view, as the concept of imposed relevance cannot be thought without reference to antagonism on the part of those subject to power. ${ }^{6}$ To take into consideration their point of view may not suffice, as Max Weber has shown when he defined power independently from the existence of a reluctant will. ${ }^{7}$ Nevertheless, phenomenological reflection reminds us not to ignore the subjective point of view in its significance for analyzing power relations. Take, as an example, social typification which-regardless of the intentions of the typifier-may impose relevances on the afflicted individual or group or it may not. In order to decide on what the case is, one has to consider the subjective point of view of the typified individuals and their systems of relevance. In "Equality and the Meaning Structure of the Social World," Schutz states that "the American way of life is not disturbed by the fact that foreigners identify it with the pattern presented by Hollywood films" (1964a: 255). On the other hand, in the same essay he touches on the "Separate Car Act," which was enacted in Louisiana in 1890 and forbid African-Americans to travel in the same rail cars as

5 "Among the bodies belonging to this 'Nature' and included in my peculiar ownness, I then find my animate organism as uniquely singled out-namely as the only one of them that is not just a body" (Husserl 1999: 97).

6 The examples Schutz uses in his applied studies are in fact exclusively concerned with a victim's perspective, which may have autobiographical (and in this context: ethical) reasons (cf. Barber 2004).

${ }^{7}$ An argument aiming in the same direction can be found in Structures of the Life-World, where Thomas Luckmann refers to what one could call a systematic self-deception of the individual: within the natural attitude the conscious intentionality centres on the free inorder-to-motives more often and less so on the bound because-of-motives. From this one may argue that in everyday life the individual chronically overestimates its own freedom of will respectively of action. 
white people. Referring to this juridical example, Schutz remarks: "the imposed system of relevances has indeed repercussions upon the system of relevances of those it is inflicted upon [...]. [B]eing treated as a type induces self-typification with an inverted sign" (ibid.: 261).

Consequently, Schutz defines discrimination by referring to the objective point of view as well as to the subjective one, and in this way I believe that social phenomena of power must be regarded from both sides. The concept of socially imposed relevance provides a very helpful tool for the study of the subjective perspective, but we must consider that this specific type of relevance cannot be developed by simply adding the social world to the "natural" world, the latter being the subject matter of Schutz's philosophical Reflections on the Problem of Relevance. We must not forget about the difference between phenomenological and sociological statements. Because they refer to social constructions, sociological statements are subject to the postulate of adequacy (Schutz 1996b: 22) which has no influence on the philosophical theorems of phenomenology. Consequently, if one applies phenomenological reflections exactly as they are to social constructions, one runs the risk of violating said postulate, for example by defining a priori criteria for distinguishing between imposed and free relevances-a distinction which is actually a matter of social construction. Therefore, I believe that considering Schutz's phenomenological distinction between free and imposed relevance as an effort to solve Immanuel Kant's antinomy of freedom (cf. Kant 1996: 473ff.) would be ill-advised, as the following remark by Thomas Luckmann clearly shows:
"In short, plans are imbedded in plan hierarchies, which finally refer to the limits of the human situation in the life-world. This means that either immediately, or at least mediately, all conduct can be ordered in contexts of 'free' motivational relevance. Vice versa, however, in principle every act and all conduct have a 'history.' A 'first' project is - as long as we are satisfied with the description of the life-world - unimaginable. Fundamentally, all conduct and every act can be understood in contexts of 'bound' motivational relevance" (Schutz/Luckmann 1973: 222f.; emphasis by the author).

In my opinion, Schutz's considerations should be read as basic reflections which provide useful instruments for empirical research. Thus, let me reformulate my statement from the beginning more precisely: the concept of imposed relevance, originally developed by Schutz by means of phenomenological description, allows the empirical examination of power relations, yet it has to be adapted for sociological intentions by making it compatible with the first-order-constructs of common sense. In a way, this is what the postulate of subjective interpretation calls for, that is, to refer "all kinds of human action or their result to the subjective meaning such action or result of an action had for the actor" (Schutz 1962a: 43). Instead of an a priori demarcation between free and imposed relevances by means of philosophical reflection, the sociologist has to reconstruct 
everyday processes of interpretation which may well be at odds with the philosophical point of view. Here, this conclusion results from reflections on the type of motivational relevance, yet it applies to the types of thematic and interpretational relevance as well, which I have omitted in the preceding and which have to be analyzed separately. I hope that some of the considerations presented in this paper might prove helpful in pursuing this task.

\section{References}

Barber, Michael (2004). The Participating Citizen. A Biography of Alfred Schutz. Albany: State University of New York Press.

Dostoyevsky, Fyodor (2010). The Brothers Karamazov. Ed. by S. McReynolds. Transl. by C. Garnett. $2^{\text {nd }}$ ed. New York/London: Norton.

Durkheim, Emile (1998). The Division of Labor in Society. Transl. by W. D. Halls. Basingstoke: Macmillan.

Husserl, Edmund (1999). Cartesian Meditations. An Introduction to Phenomenology. Ed. by D. Cairns. Dordrecht et al.: Kluwer.

Kant, Immanuel (1996). Critique of Pure Reason. Indianapolis et al.: Hackett Publ.

List, Elisabeth (2004). "Einleitung der Herausgeberin." In: Alfred Schutz, Relevanz und Handeln 1: Zur Phänomenologie des Alltagswissens (ASW Vol. VI.1). Ed. by E. List. Konstanz: UVK, pp. 7-40.

Litt, Theodor (1926). Individuum und Gemeinschaft. Grundlegung der Kulturphilosophie. $3^{\text {rd }}$ ed. Leipzig: Teubner.

Luckmann, Thomas (2007). „Wirklichkeiten: individuelle Konstitution, gesellschaftliche Konstruktion." In: Lebenswelt, Identität und Gesellschaft. Schriften zur Wissens- und Protosoziologie. Ed. by J. Dreher. Konstanz: UVK, pp. 127-137.

Schutz, A. (1962a). "Common-sense and Scientific Interpretation of Human Action." In: Collected Papers I: The Problem of Social Reality. Ed. by M. Natanson. The Hague: Nijhoff, pp. 3-47.

- (1962b). "Symbol, Reality and Society." In: Collected Papers I: The Problem of Social Reality. Ed. by M. Natanson. The Hague: Nijhoff, pp. 287-356.

___. (1964a). "Equality and the Meaning Structure of the Social World." In: Collected Papers II: Studies in Social Theory. Ed. by A. Brodersen. The Hague: Nijhoff, pp. 226-273.

- - (1964b). "The Well-informed Citizen. An Essay on the Social Distribution of Knowledge.” In: Collected Papers II: Studies in Social Theory. Ed. by A. Brodersen. The Hague: Nijhoff, pp. 120-134.

__ . (1996a). "On the Concept of Horizon.” In: Collected Papers IV. Ed. by H. Wagner and G. Psathas in collab. with F. Kersten. Dordrecht et al.: Kluwer, pp. 196-200.

- (1996b). "The Problem of Rationality in the Social World." In: Collected Papers $I V$. Ed. by H. Wagner and G. Psathas in collab. with F. Kersten. Dordrecht et al.: Kluwer, pp. 6-24.

- - (1997). The Phenomenology of the Social World. Transl. by G. Walsh and F. Lehnert, with an introd. by G. Walsh. Evanston, Ill.: Northwestern University Press. 
——. (2003). „Das Problem der Personalität in der Sozialwelt.“ In: Theorie der Lebenswelt 1: Die pragmatische Schichtung der Lebenswelt (ASW Vol. V.1). Konstanz: UVK, pp. 35-73.

——. (2011). "Reflections on the Problem of Relevance." In: Collected Papers V: Phenomenology and the Social Sciences. Ed. by L. Embree. Dordrecht et al.: Springer, pp. 93-199.

Schutz, Alfred and Thomas Luckmann (1973). The Structures of the Life-World. Vol. I. Transl. by R. M. Zaner and H. T. Engelhardt. Evanston, Ill.: Northwestern University Press.

. (1989). The Structures of the Life-World. Vol. II. Transl. by R. M. Zaner and D. J. Parent. Evanston, Ill.: Northwestern University Press.

Srubar, Ilja (2007). „Ist die Lebenswelt ein harmloser Ort? Zur Genese und Bedeutung des Lebensweltbegriffs." In: Phänomenologie und soziologische Theorie. Wiesbaden: VS Verlag, pp. 13-33. 